\title{
Analisis Efektivitas Pengendalian Risiko Kecelakaan Kerja Pada Pekerja Proyek Konstruksi Menggunakan Metode Fine dan Fault Tree Analysis
}

\author{
Nopita Sari br Ginting ${ }^{*}$, Retna Kristiana \\ Jurusan Teknik Sipil, Fakultas Teknik, Universitas Mercu Buana, \\ Jl. Meruya Selatan, Kembangan, Jakarta Barat, Indonesia 2751
}

\begin{abstract}
Abstrak
Semua proyek konstruksi pasti memiliki risiko. Salah satunya adalah risiko terjadinya kecelakaan. Masalah Keselamatan dan Kesehatan Kerja (K3) pada sektor konstruksi masih belum menjadi perhatian utama. Hal itu dapat dilihat dari angka kecelakaan kerja di sektor konstruksi adalah yang paling tinggi di antara bidang kerja lainnya. Berdasarkan Laporan Insiden HSE Project, terdapat tujuh insiden pada proyek Office Tower J-Box Jakarta Pusat, sehingga prinsip zero accident pada proyek tersebut tidak tercapai. Tujuan dari penelitian ini adalah untuk mengidentifikasi pekerjaan yang berisiko menimbulkan bahaya pada pekerja proyek, menilai tingkat risiko, menilai efektivitas pengendalian risiko, dan menentukan pengendalian risiko yang tepat pada proyek tersebut. Data yang digunakan dalam penelitian ini adalah data primer berupa kuesioner pada responden dan data sekunder berupa Laporan Mingguan K3, Laporan Bulanan K3, dan Laporan Data insiden. Penelitian ini menggunakan kombinasi metode Fine dan Fault Tree Analysis. SPSS V22 digunakan untuk menguji validitas data primer. Metode Fine digunakan untuk menghitung nilai risiko kecelakaan kerja. Metode Fault Tree Analysis dipakai untuk menganalisis nilai risiko sehingga diketahui penyebab dasar dari suatu kejadian yang berpotensi bahaya dan merekomendasikan tindakan spesifik yang dapat dilakukan kontraktor dalam meminimalisir bahaya tersebut. Analisis hasil penelitian menunjukkan bahwa nilai efektivitas risk control pada pekerja proyek konstruksi pembangunan Office Tower J-Box Jakarta berada pada tingkat risiko <20 atau acceptable. Tindakan spesifik yang dapat dilakukan oleh kontraktor untuk meminamilisir potensi bahaya yang ada adalah membuat metode kerja yang aman untuk setiap pekerjaan, melakukan tool box meeting sebelum memulai suatu pekerjaan, mengajukan ijin kerja K3 sebelum melakukan pekerjaan, menggunakan APD yang sesuai untuk setiap pekerjaan, pemasangan rambu-rambu $K 3$ pada area pekerjaan dan pengawasan oleh tim HSE.
\end{abstract}

Kata kunci: identifikasi bahaya; analisis risiko; efektivitas pengendalian risiko; fault tree analysis

\begin{abstract}
[Title: Effectiveness Analysis of Work Accident Risk Control on Construction Project Workers using Fine and Fault Tree Analysis Method (Case Study: Office Tower J-Box Project in Jakarta)] All construction projects are at risk. One of them is the risk of accidents. Occupational Safety and Health Issues (K3) is still not a major concern. It can be seen from the number of work accidents in the construction sector is the highest among other fields. Based on the Incident Report of HSE Project, there are 7 (seven) incidents in the Central Jakarta Office Tower J-Box project. The incidents mean that the principle of zero accidents on the project is not achieved. This study aimed to identify hazard risks to Project workers, assess the risk level, assess the effectiveness of risk control, and determine appropriate risk controls on the project. The data used in this study are primary data in the form of questionnaires on respondents and secondary data in the form of Weekly K3 Reports, K3 Monthly Report, and Incident Data Report. This research used a combination of the Fine method and Fault Tree Analysis method. SPSS V22

${ }^{*}$ Penulis Korespondensi.

E-mail: novitagintingmunthe@gmail.com

is used to test the validity of primary data. The Fine method is used to calculate the value of the risk of workplace accidents. The Fault Tree
\end{abstract}




\title{
TEKNIK, 41 (2), 2020, 193
}

\begin{abstract}
Analysis method is used to analyze the risk value. It is known as the primary cause of a potentially hazardous event and recommends specific actions that the contractor can take to minimize these hazards. Analysis of the study results shows that the value of risk control effectiveness in construction workers at the Jakarta J-Box Tower Office is at risk level <20 or acceptable. Specific actions that can be taken by contractors to manage potential hazards are to make a safe working method for each job, do a meeting toolbox before starting a job, apply for a K3 work permit before doing work, use PPE that is suitable for each job, install signs $K 3$ signs in the work area and supervision by the HSE team.
\end{abstract}

Keywords: hazard identification; risk analysis; effectiveness risk control; fault tree analysis

\section{Pendahuluan}

Menurut International Labour Organization (ILO) tahun 2015, diperkirakan secara global ada 60.000 kecelakaan kerja fatal per tahunnya. Sekitar 1 dari 6 kecelakaan fatal yang dilaporkan, terjadi pada sektor konstruksi. Berdasarkan data Occupational Safety and Health Administration (OSHA) di Amerika menunjukkan bahwa jumlah kematian total dalam sektor konstruksi pada tahun 2014 sebesar 874 jiwa. Dari jumlah kematian tersebut 349 jiwa $(39,9 \%)$ di sebabkan karena jatuh dari ketinggian, 74 jiwa $(8,5 \%)$ karena listrik, 73 jiwa $(8,4 \%)$ kejatuhan benda dan 12 jiwa $(1,4 \%)$ karena kecelakaan lain (United States Department of Labor, 2014).

Di Indonesia sendiri, Badan Penyelenggara Jaminan Sosial (BPJS) Ketenagakerjaan tahun 2015, menyatakan bahwa setiap 100.000 kasus kecelakaan terhadap tenaga kerja di Indonesia, 30\% diantaranya terjadi di sektor konstruksi. Kementrian Ketenagakerjaan tahun 2014 menjelaskan bahwa jumlah kecelakaan kerja yang dialami pekerja konstruksi relatif tinggi yaitu $31,9 \%$ dari total kecelakaan dengan jenis kasus kecelakaan tertinggi yaitu jatuh dari ketinggian $26 \%$, terbentur $12 \%$ dan tertimpa $9 \%$ (Safitri \& Widowati, 2017).

Proyek Office Tower J-Box Jakarta adalah sebuah proyek gedung perkantoran yang berlokasi di Jalan Kebon Sirih Jakarta Pusat. Bangunan ini terdiri dari 25 lantai kantor, 5 lantai split level (area parkir) di podium dan 2 lantai Basement. Luas total keseluruhan bangunan adalah $64.953,4 \mathrm{~m}^{2}$ dengan tinggi bangunan $130,17 \mathrm{~m}$. Proyek Office Tower J-Box Jakarta dimulai pada awal tahun 2017 dan ditargetkan selesai di awal tahun 2019.

Proyek Office Tower J-Box termasuk proyek high risk building dan berada di lokasi yang sangat strategis. Untuk itu dibutuhkan sistem pengendalian Kesehatan dan Keselamatan Kerja (K3) yang baik untuk mendukung berjalannya aktivitas proyek.

Berdasarkan Laporan Insiden HSE Project Periode Januari - Desember 2017 terdapat 7 insiden pada proyek Office Tower J-Box Jakarta. Prinsip zero accident belum dapat tercapai pada proyek tersebut. Dari data tersebut peneliti tertarik untuk menganalisis efektivitas pengendalian risiko pada pekerja kontruksi di proyek Office Tower J-Box Jakarta dengan melakukan analisis dan validitas data dengan program SPSS (Statistical Product and Service Solution), menilai risk control dan menggunakan metode Fine serta memberikan tindakan spesifik yang dilakukan kontraktor dengan metode FTA (Fault Tree Analysis) guna meminimalisir potensi bahaya.

\section{Metode Penelitian}

Penelitian ini dilakukan di proyek pembangunan Office Tower J-Box Jakarta Pusat, dengan jangka waktu penelitian selama 5 (lima) bulan. Penelitian ini menggunakan metode kuantitatif, dengan mengumpulkan data primer dan sekunder. Pengumpulan data primer berupa data risiko kecelakaan kerja, dilakukan dengan menggunakan kuesioner kepada para responden serta wawancara kepada pihak-pihak yang terkait. Pengumpulan data sekunder dilakukan dengan mengumpulkan referensi- referensi sebagai bahan acuan dalam penelitian ini berupa literatur-literatur atau jurnaljurnal yang terkait dengan penelitian ini.

Populasi penelitian ini adalah para staff engineering dan staff HSE yang berjumlah 31 orang. Populasi ini sekaligus ditetapkan sebagai sampel karena jumlah populasi kurang dari 100 (Arikunto, 2010). Office Tower J-Box, Jakarta Pusat pada pekerjaan struktur atas.

Analisis atas data dilakukan dengan beberapa tahapan, diantaranya uji validitas data primer, yang dilakukan dengan menggunakan SPSS versi 22. Penghitungan nilai risiko kecelakaan kerja dilakukan dengan menggunakan metode Fine sedangkan analisis untuk mengetahui penyebab dasar dari suatu bahaya dilakukan dengan metode Fault Tree Analysis (FTA). FTA diperlukan untuk meminimalisir bahaya yang ada.

\section{Metode Fine}

Metode Fine digunakan dalam perhitungan skor risiko kecelakaan kerja dengan mencari tiga parameter yaitu, E (Exposure), C (Consequences), dan $\mathrm{P}$ (Probability) (Fine, 1973). Skor ditentukan dengan rumus Fine seperti terlihat pada Persamaan 1.

$$
\mathrm{RS}=\mathrm{E} \times \mathrm{C} \times \mathrm{P}
$$




\section{TEKNIK, 41 (2), 2020, 194}

dimana RS merupakan Skor Risiko (Risk Score), E adalah frekuensi terjadinya kecelakaan akibat paparan bahaya yang sama dan menimbulkan jejas yang sama; $\mathrm{C}$ adalalah konsekuensi yang mungkin terjadi dari jenis jejas dan bagian badan tertentuyang terluka; $\mathrm{P}$ adalah probabilitas atau kemungkinan terjadinya kecelakaan dalam satuan waktu tertentu.

Fine memberikan penjelasan lebih rinci akan konsep exposure, consequence dan probability. Menurut Fine (1973), exposure (paparan) adalah frekuensi pemaparan terhadap bahaya atau sumber risiko. Kriteria, nilai faktor dan exposure (paparan) seperti pada Tabel 1. Adapun consequence adalah akibat yang mungkin ditimbulkan dari suatu kejadian atau peristiwa. Kriteria, nilai faktor dan consequence seperti pada Tabel 2. Adapun probability adalah kemungkinan terjadinya

Tabel 1. Kriteria dan Nilai Faktor dan Exposure (Fine, 1973)

\begin{tabular}{|c|c|c|c|}
\hline No & Tingkatan & Deskripsi & Rating \\
\hline 1 & Very Rare & $\begin{array}{l}\text { Tidak diketahui kapan } \\
\text { terjadinya }\end{array}$ & 0,5 \\
\hline 2 & Rare & Diketahui kapan terjadinya & 1 \\
\hline 3 & Infraquent & $\begin{array}{l}\text { Satu kali dalam sebulan } \\
\text { sampai satu kali dalam setahun }\end{array}$ & 2 \\
\hline 4 & Occasionally & $\begin{array}{l}\text { Terjadi satu kali seminggu } \\
\text { sampai satu kali sebulan }\end{array}$ & 3 \\
\hline 5 & Frequently & $\begin{array}{l}\text { Terjadi kira-kira satu kali } \\
\text { dalam sehari }\end{array}$ & 6 \\
\hline 6 & Continuously & Sering terjadi dalam satu hari & 10 \\
\hline
\end{tabular}

Tabel 2. Kriteria dan Nilai Faktor dan Consequence (Fine, 1973)

\begin{tabular}{|c|c|c|c|}
\hline & Tingkatan & Deskripsi & Rating \\
\hline 1 & Noticeable & $\begin{array}{l}\text { Terjadi cidera atau penyakit ringan, } \\
\text { memar bagian tubuh, kerusakan } \\
\text { ringan atau terhentinya proses kerja } \\
\text { sementara waktu. }\end{array}$ & 1 \\
\hline 2 & Important & $\begin{array}{l}\text { Membutuhkan penanganan medis, } \\
\text { terjadi emisi buangan di lokasi } \\
\text { tetapi tidak menyebabkan } \\
\text { kerusakan. }\end{array}$ & 5 \\
\hline 3 & Serious & $\begin{array}{l}\text { Terjadi dampak yang serius tapi } \\
\text { bukan cidera dan penyakit parah } \\
\text { yang permanen, sedikit berdampak } \\
\text { buruk pada lingkungan. }\end{array}$ & 15 \\
\hline 4 & $\begin{array}{l}\text { Very } \\
\text { serious }\end{array}$ & $\begin{array}{l}\text { Terjadi cacat permanen/penyakit } \\
\text { parah, kerusakan lingkungan yang } \\
\text { tidak permanen }\end{array}$ & 25 \\
\hline 5 & Disaster & $\begin{array}{l}\text { Kematian, kerusakan permanen } \\
\text { yang bersifat lokal terhadap } \\
\text { lingkungan. }\end{array}$ & 50 \\
\hline 6 & Catastrophe & $\begin{array}{l}\text { Kerusakan fatal pada fasilitas, } \\
\text { aktivitas dihentikan, terjadi } \\
\text { kerusakan lingkungan yang parah }\end{array}$ & 100 \\
\hline
\end{tabular}

bahaya yang menyertai suatu kejadian atau peristiwa. Kriteria, nilai faktor dan probability pada Tabel 3.

Nilai risiko dapat dihitung dengan perkalian nilai exposure, consequence dan probability. Setelah nilai risiko diperoleh dari setiap risiko maka dapat ditentukan dalam bentuk skor seperti pada Tabel 4 .

\section{Fault Tree Analysis (FTA)}

Fault Tree Analysis (FTA) adalah metode yang digunakan dalam memprediksi atau digunakan sebagai alat investigasi setelah terjadi kecelakaan, konsep ini dilakukan dengan mencari keterkaitan secara berantai yang menyebabkan kecelakaan bisa terjadi (Dharma, Putera \& Parami, 2017)

Tabel 3. Kriteria dan Nilai Faktor dan Probability (Fine, 1973)

\begin{tabular}{|c|c|c|c|}
\hline No & Tingkatan & Deskripsi & Rating \\
\hline 1 & $\begin{array}{l}\text { Practically } \\
\text { imposible }\end{array}$ & $\begin{array}{l}\text { Sangat tidak mungkin } \\
\text { terjadi }\end{array}$ & 0,1 \\
\hline 2 & $\begin{array}{l}\text { Remotely } \\
\text { possible }\end{array}$ & $\begin{array}{l}\text { Suatu kejadian yang sangat } \\
\text { kecil kemungkinan } \\
\text { terjadinya }\end{array}$ & 1 \\
\hline 3 & Conceivable & $\begin{array}{l}\text { Tidak pernah terjadi } \\
\text { kecelakaan dalam tahun- } \\
\text { tahun pemaparan tetapi } \\
\text { mungkin terjadi }\end{array}$ & 0,5 \\
\hline 4 & $\begin{array}{l}\text { Unusual but } \\
\text { possible }\end{array}$ & $\begin{array}{l}\text { Tidak bisa namun memiliki } \\
\text { kemungkinan terjadi kali } \\
\text { dalam sehari }\end{array}$ & 3 \\
\hline 5 & Likely & $\begin{array}{l}\text { Kemungkinan terjadi } \\
\text { kecelakaan } 50 \%\end{array}$ & 6 \\
\hline 6 & Almost certain & $\begin{array}{l}\text { Kejadian paling sering } \\
\text { terjadi }\end{array}$ & 10 \\
\hline
\end{tabular}

Tabel 4. Level/Prioritas Risiko (Cross, 1998)

\begin{tabular}{|c|c|c|}
\hline $\begin{array}{l}\text { Tingkat } \\
\text { Risiko }\end{array}$ & Comment & Action \\
\hline$<20$ & Acceptable & $\begin{array}{l}\text { Intensitas kegiatan yang } \\
\text { menimbulkan risiko } \\
\text { dikurangi seminimal } \\
\text { mungkin } \\
\text { berkesinambungan }\end{array}$ \\
\hline $20-70$ & Priority 3 & $\begin{array}{l}\text { Perlu diawasi dan } \\
\text { diperhatikan secara }\end{array}$ \\
\hline $70-180$ & Substansial & $\begin{array}{l}\text { Mengharuskan ada } \\
\text { perbaikan secara teknis }\end{array}$ \\
\hline $180-350$ & Priority 1 & $\begin{array}{l}\text { Perlu dilakukan } \\
\text { penanganan secepatnya }\end{array}$ \\
\hline$>350$ & Very high & $\begin{array}{l}\text { Penghentian aktivitas, } \\
\text { risiko dikurangi hingga } \\
\text { mencapai batas yang dapat } \\
\text { diterima }\end{array}$ \\
\hline
\end{tabular}




\section{TEKNIK, 41 (2), 2020, 195}

FTA menggunakan dua simbol utama yang disebut events dan gates. Ada 3 (tiga) tipe event, yaitu: (1) Primary Event, yakni sebuah tahap dalam proses penggunaan produk yang mungkin saat gagal. Primary event lebih lanjut dibagi menjadi tiga kategori yaitu basic events, undeveloped events dan external events; (2) Intermediet Event, yakni hasil dari kombinasi kesalahan-kesalahan, beberapa diantaranya mungkin primary event. Intermediate event ini ditempatkan ditengah-tengah sebuah fault tree; serta (3) Expanded Event, yang membutuhkan sebuah fault tree yang terpisah dikarenakan kompleksitasnya. Expanded event adalah undesired event dan diletakan pada bagian atas fault tree.

Langkah-langkah dalam metode Fault Tree Analysis yaitu (1) mendata potensi bahaya dan nilai risk analysis; (2) menyajikan data analisis potensi bahaya dalam model pohon kegagalan dengan menggunakan simbol-simbol yang ada, seperti pada Tabel 5; (3) menentukan basic event dari analisis model pohon kegagalan; dan (4) berdasarkan basic event yang telah dilakukan oleh kontraktor untuk meminimalisir potensi bahaya.

Tabel 5. Simbol Fault Tree Analysis (FTA) (Pitasari, Wahyuning, \& Desrianty, 2014)

\begin{tabular}{|c|c|}
\hline Lambang & Arti \\
\hline & $\begin{array}{l}\text { Kejadian yang tidak akan dikembangkan lebih } \\
\text { jauh } \\
\text { Kejadian yang tidak diharapkan dianggap } \\
\text { sebagai penyebab dasar } \\
\text { Kejadian yang tidak dikehendaki }\end{array}$ \\
\hline & $\begin{array}{l}\text { Menunjukkan bahwa uraian lanjutan kegiatan } \\
\text { berada di halaman ini } \\
\text { Kejadian di atas muncul hanya salah satu yang } \\
\text { dapat menyebabkan kejadian (atau) }\end{array}$ \\
\hline & $\begin{array}{l}\text { Kejadian di atas timbul jika semua input } \\
\text { bersama menyebabkan kejadian diatasnya (dan) }\end{array}$ \\
\hline
\end{tabular}

\section{Analisis dan Pembahasan}

\subsection{Identifikasi Risiko Kecelakaan Kerja}

Analisis efektivitas pengendalian risiko pada pekerja konstruksi dilakukan dengan menentukan risiko kecelakaan di lingkungan kerja. Identifikasi risiko kecelakaan kerja dalam penelitian ini dilakukan berdasarkan data yang diperoleh dari kuesioner yang disebarkan kepada pakar, yakni pihak-pihak yang terkait dalam pembangunan di proyek. Adapun data pakar dari proyek Office Tower J-Box, Jakarta Pusat ini dalam survey penentuan risiko kecelakaan kerja, seperti pada Tabel 6.

\subsection{Kuesioner Pakar Tahap Awal}

Tabel 6 menunjukkan hasil idenfikasi atas 30 risiko kecelakaan kerja pada pekerja proyek konstruksi yang mungkin terjadi pada proyek Office Tower J-Box Jakarta yang di ambil dari berbagai sumber.
Tabel 6. Risiko Kecelakaan Kerja

\begin{tabular}{|c|c|c|}
\hline No & Risiko Kecelakaan Kerja & Sumber \\
\hline$\overline{\mathrm{X} 1}$ & Pekerjaan Bekisting & \\
\hline X1.1 & $\begin{array}{l}\text { Pekerja tertimpa perancah pada } \\
\text { saat penyusunan }\end{array}$ & $\begin{array}{l}\text { Jawat, 2017; } \\
\text { Ratnasari, } \\
\text { Hardjanto \& } \\
\text { Darnoto, 2016; }\end{array}$ \\
\hline $\mathrm{X} 1.2$ & $\begin{array}{l}\text { Pekerja jatuh dari ketinggian lebih } \\
\text { dari } 2 \text { meter pada saat } \\
\text { pembongkaran bekisting }\end{array}$ & $\begin{array}{l}\text { Rizky, 2013; } \\
\text { Rahaded, } 2014\end{array}$ \\
\hline $\mathrm{X} 1.3$ & $\begin{array}{l}\text { Pekerja tersandung material } \\
\text { bongkaran }\end{array}$ & $\begin{array}{l}\text { Persada, 2015; } \\
\text { Yuliani, } 2017\end{array}$ \\
\hline X1.4 & Kepala terbentur benda keras/tajam & $\begin{array}{l}\text { Aprilia, } 2018 \\
\text { Johannes, Kawatu } \\
\text { \& Malonda, } 2017\end{array}$ \\
\hline $\mathrm{X} 1.5$ & $\begin{array}{l}\text { Tergetok palu pada saat } \\
\text { penyusunan bekisting }\end{array}$ & $\begin{array}{l}\text { Yolanda, 2014; } \\
\text { Anwar, Farida, \& } \\
\text { Ismail, 2014; }\end{array}$ \\
\hline X1.6 & Terbentur cetakan bekisting & $\begin{array}{l}\text { Zulfa, } 2017 \\
\text { Rethyna, 2018; }\end{array}$ \\
\hline $\mathrm{X} 1.7$ & $\begin{array}{l}\text { Tertimpa alat bantu bongkar atau } \\
\text { linggis }\end{array}$ & $\begin{array}{l}\text { Samsuri, } 2014 \\
\text { Rizky, } 2013\end{array}$ \\
\hline $\mathrm{X} 1.8$ & Tertimpa material bekisting & $\begin{array}{l}\text { Mariawati, Umyati } \\
\& \text { Andiyani, } 2014\end{array}$ \\
\hline X1.9 & Pekerja tertusuk paku & $\begin{array}{l}\text { Taufik, } 2013 \\
\text { Reni, } 2017\end{array}$ \\
\hline $\mathrm{X} 1.10$ & $\begin{array}{l}\text { Tangan atau kaki terjepit cetakan } \\
\text { bekisting }\end{array}$ & $\begin{array}{l}\text { Ratnasari, } \\
\text { Hardjanto \& } \\
\text { Darnoto, 2016; } \\
\text { Danang, 2014 } \\
\text { Yolanda, 2014; }\end{array}$ \\
\hline
\end{tabular}

X2 Pekerjaan Pembesian

X2.1 Jari atau tangan terputus akibat Bar Zulfa, 2017

Cutter Yolanda, 2014;

X2.2 Tertusuk besi pada saat pekerjaan Apriyan, Setiawan penganyaman besi \& Ervianto, 2017;

Adityanto, Irawan, Hatmoko, Kistiani, 2013

X2.3 Terbentur tulangan pada saat ereksi Anwar, Farida, \& tulangan Ismail, 2014;Reni, 2017

X2.4 Pekerja terkena percikan las Rethyna, 2018;

$\begin{array}{ll}\text { X2.5 Jari tangan terjepit besi } & \text { Al Farisi, } 2016\end{array}$

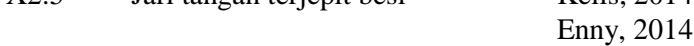

X2.6 Pekerja jatuh dari kerangka Rizky, 2013 tulangan pada saat memasang dan Jannah, Unas \& merakit tulangan Hasyim, 2017

X2.7 Luka bakar ringan akibat panasnya Persada, 2015; besi Johannes, Kawatu \& Malonda, 2017

X2.8 Tersandung saat pekerjaan Adityanto, Irawan, pembesian balok dan plat Hatmoko, Kistiani, 2013; Fahmi, 2017

$\begin{array}{lll}\text { X2.9 } & \begin{array}{l}\text { Tersengat listrik pada saat } \\ \text { menggunakan Bar cutter dan Bar }\end{array} & \text { Bryan, } 2013 \\ & \text { Bria \& Loden, } 2017\end{array}$ Bender

X2.10 Tertimpa besi yang sudah dirakit Zulfa, 2017 saat pengambilan dari Tower Mariawati, Umyati Crane 


\section{TEKNIK, 41 (2), 2020, 196}

\begin{tabular}{|c|c|c|}
\hline No & Risiko Kecelakaan Kerja & Sumber \\
\hline $\mathbf{X 3}$ & Pekerjaan Pengecoran & \\
\hline X3.1 & Tertimpa material beton & Raihana, 2016 \\
\hline $\mathrm{X} 3.2$ & $\begin{array}{l}\text { Iritasi mata dan kulit akibat debu } \\
\text { dan kotoran pada saat pemberihan } \\
\text { lokasi cor dengan mesin } \\
\text { Compressor }\end{array}$ & $\begin{array}{l}\text { Anwar, Farida, \& } \\
\text { Ismail, 2014; } \\
\text { Yuliani, } 2017\end{array}$ \\
\hline $\mathrm{X} 3.3$ & $\begin{array}{l}\text { Robohnya cetakan beton pada saat } \\
\text { pengecoran }\end{array}$ & $\begin{array}{l}\text { Soputan, Sompie \& } \\
\text { Mandagi, 2014; } \\
\text { Widi, } 2016\end{array}$ \\
\hline X3.4 & Terbentur bucket cor & $\begin{array}{l}\text { Jannah, Unas \& } \\
\text { Hasyim, 2017; } \\
\text { Zulfa, } 2017\end{array}$ \\
\hline $\mathrm{X} 3.5$ & $\begin{array}{l}\text { Gangguan pada mata dan } \\
\text { pendengaran akibat getaran } \\
\text { vibrator }\end{array}$ & $\begin{array}{l}\text { Novie, } 2017 \\
\text { Samsuri, } 2014\end{array}$ \\
\hline X3.6 & $\begin{array}{l}\text { Pekerja terpeleset akibat licinnya } \\
\text { lantai kerja }\end{array}$ & $\begin{array}{l}\text { Apriyan, Setiawan } \\
\text { \& Ervianto, 2017; } \\
\text { Bria \& Loden, } 2017\end{array}$ \\
\hline X3.7 & $\begin{array}{l}\text { Gangguan pernapasan akibat } \\
\text { pembersihan area cor dengan } \\
\text { mesin Compressor }\end{array}$ & $\begin{array}{l}\text { Adityanto, Irawan, } \\
\text { Hatmoko, Kistiani, } \\
\text { 2013; Persada, 2015; }\end{array}$ \\
\hline $\mathrm{X} 3.8$ & $\begin{array}{l}\text { Mata pekerja terkena percikan } \\
\text { beton }\end{array}$ & $\begin{array}{l}\text { Reni, } 2017 \\
\text { Taufik, } 2013\end{array}$ \\
\hline X3.9 & $\begin{array}{l}\text { Terjatuh dari staging } \\
\text { cor/ketinggian }\end{array}$ & $\begin{array}{l}\text { Ratnasari, } \\
\text { Hardjanto \& } \\
\text { Darnoto, 2016; } \\
\text { Mariawati, Umyati } \\
\text { \& Andiyani, } 2014\end{array}$ \\
\hline $\mathrm{X} 3.10$ & Terbentur pipa tremi & $\begin{array}{l}\text { Rethyna, 2018; } \\
\text { Zulfa, } 2017\end{array}$ \\
\hline
\end{tabular}

\subsection{Uji Validitas}

Hasil identifikasi risiko kecelakaan kerja yang diperoleh dari kuesioner ditetapkan menjadi variable penelitian, sehingga terdapat 30 variabel penelitian. Masing-masing variable ini melalui uji validitas dengan menggunakan software SPSS Versi 22.

Dari Tabel 7 dapat dilihat bahwa terdapat 4 (empat) variabel bernilai akhir tidak valid yaitu X2.1, X2.9, X3.3 dan X3.6. Maka dari hasil sinkronisasi tersebut, dinyatakan 26 variabel risiko kecelakaan kerja yang digunakan dalam menganalisis efektivitas pengendalian risiko kerja.

\subsection{Uji Reliabilitas}

Menurut Christina, Djakfar \& Thoyib (2012), uji reliabilitas digunakan untuk melihat apakah alat ukur yang digunakan kuesioner menunjukan konsistensi didalam mengukur gejala yang sama. Adapun ketentuan uji realibilitas dengan metode cronbach's coeffisien alpha adalah: (1) Nilai cronbach's coeffisien alpha < 0,6 menunjukan bahwa instrumen penelitian tidak reliable dan (2) Nilai cronbach's coeffisien alpha > 0,6 menunjukan bahwa instrumen penelitian reliable.

Tabel 8 menunjukkan hasil uji, dimana nilai cronbach alpha output Exposure (E) yaitu 0.962, sehingga data reliabel atau dapat dipercaya. Nilai cronbach alpha output Consequence (C) yaitu 0.929, maka data reliabel atau dapat dipercaya. Nilai cronbach alpha output Probability (P) yaitu 0.912, maka data reliabel atau dapat dipercaya. Secara keseluruhan hasil uji pada Tabel 8 memperlihatkan nilai cronbach alpha output $>0,6$. Hal ini menunjukan bahwa instrumen penelitian reliable.

Tabel 7. Sinkronisasi Validitas Exposure, Consequence dan Probability

\begin{tabular}{|c|c|c|}
\hline No & Risiko Kecelakaan Kerja & Validitas \\
\hline $\mathbf{X 1}$ & Pekerjaan Bekisting & \\
\hline $\mathrm{X} 1.1$ & $\begin{array}{l}\text { Pekerja tertimpa perancah pada saat } \\
\text { penyusunan }\end{array}$ & Valid \\
\hline $\mathrm{X} 1.2$ & $\begin{array}{l}\text { Pekerja jatuh dari ketinggian lebih dari } 2 \\
\text { meter pada saat pembongkaran bekisting }\end{array}$ & Valid \\
\hline $\mathrm{X} 1.3$ & Pekerja tersandung material bongkaran & Valid \\
\hline $\mathrm{X} 1.4$ & Kepala terbentur benda keras/tajam & Valid \\
\hline $\mathrm{X} 1.5$ & $\begin{array}{l}\text { Tergetok palu pada saat penyusunan } \\
\text { bekisting }\end{array}$ & Valid \\
\hline $\mathrm{X} 1.6$ & Terbentur cetakan bekisting & Valid \\
\hline $\mathrm{X} 1.7$ & Tertimpa alat bantu bongkar atau linggis & Valid \\
\hline $\mathrm{X} 1.8$ & Tertimpa material bekisting & Valid \\
\hline X1.9 & Pekerja tertusuk paku & Valid \\
\hline $\mathrm{X} 1.10$ & $\begin{array}{l}\text { Tangan atau kaki terjepit cetakan } \\
\text { bekisting }\end{array}$ & Valid \\
\hline $\mathbf{X} 2$ & Pekerjaan Pembesian & \\
\hline $\mathrm{X} 2.1$ & $\begin{array}{l}\text { Jari atau tangan terputus akibat Bar } \\
\text { Cutter }\end{array}$ & Tidak Valid \\
\hline $\mathrm{X} 2.2$ & $\begin{array}{l}\text { Tertusuk besi pada saat pekerjaan } \\
\text { penganyaman besi }\end{array}$ & Valid \\
\hline $\mathrm{X} 2.3$ & $\begin{array}{l}\text { Terbentur tulangan pada saat ereksi } \\
\text { tulangan }\end{array}$ & Valid \\
\hline $\mathrm{X} 2.4$ & Pekerja terkena percikan las & Valid \\
\hline $\mathrm{X} 2.5$ & Jari tangan terjepit besi & Valid \\
\hline $\mathrm{X} 2.6$ & $\begin{array}{l}\text { Pekerja jatuh dari kerangka tulangan pada } \\
\text { saat memasang dan merakit tulangan }\end{array}$ & Valid \\
\hline $\mathrm{X} 2.7$ & Luka bakar ringan akibat panasnya besi & Valid \\
\hline $\mathrm{X} 2.8$ & $\begin{array}{l}\text { Tersandung saat pekerjaan pembesian } \\
\text { balok dan plat }\end{array}$ & Valid \\
\hline X2.9 & $\begin{array}{l}\text { Tersengat listrik pada saat menggunakan } \\
\text { Bar cutter dan Bar Bender }\end{array}$ & Tidak Valid \\
\hline $\mathrm{X} 2.10$ & $\begin{array}{l}\text { Tertimpa besi yang sudah dirakit saat } \\
\text { pengambilan dari Tower Crane }\end{array}$ & Valid \\
\hline $\mathbf{X 3}$ & Pekerjaan Pengecoran & \\
\hline $\mathrm{X} 3.1$ & Tertimpa material beton & Valid \\
\hline $\mathrm{X} 3.2$ & $\begin{array}{l}\text { Iritasi mata dan kulit akibat debu dan } \\
\text { kotoran pada saat pemberihan lokasi cor } \\
\text { dengan mesin Compressor }\end{array}$ & Valid \\
\hline X3.3 & $\begin{array}{l}\text { Robohnya cetakan beton pada saat } \\
\text { pengecoran }\end{array}$ & Tidak Valid \\
\hline X3.4 & Terbentur bucket cor & Valid \\
\hline X3.5 & $\begin{array}{l}\text { Gangguan pada mata dan pendengaran } \\
\text { akibat getaran vibrator }\end{array}$ & Valid \\
\hline X3.6 & $\begin{array}{l}\text { Pekerja terpeleset akibat licinnya lantai } \\
\text { kerja }\end{array}$ & Tidak Valid \\
\hline X3.7 & $\begin{array}{l}\text { Gangguan pernapasan akibat pembersihan } \\
\text { area cor dengan mesin Compressor }\end{array}$ & Valid \\
\hline $\mathrm{X} 3.8$ & Mata pekerja terkena percikan beton & Valid \\
\hline X3.9 & Terjatuh dari staging cor/ketinggian & Valid \\
\hline $\mathrm{X} 3.10$ & Terbentur pipa tremi & Valid \\
\hline
\end{tabular}




\section{TEKNIK, 41 (2), 2020, 197}

Tabel 8. Uji Reliabilitas

\begin{tabular}{lcc}
\hline & Cronbach's Alpha & N of Items \\
\hline $\begin{array}{l}\text { Uji Reliabilitas } \\
\text { Exposure (E) }\end{array}$ & 0.962 & 30 \\
$\begin{array}{l}\text { Uji Reliabilitas } \\
\text { Consequence (C) }\end{array}$ & 0.929 & 30 \\
$\begin{array}{l}\text { Uji Reliabilitas } \\
\text { Probability (P) }\end{array}$ & 0.912 & 30 \\
\hline
\end{tabular}

\subsection{Analisis Risiko}

Analisis data yang digunakan pada penelitian ini adalah menggunakan metode Fine. Data yang dianalisis hanya data yang lolos uji validasi dari program SPSS 22. Variabel yang tidak lolos uji validasi dianggap tidak bernilai (0).

Hasil analisis disajikan pada Tabel 10, dimana variabel risiko kecelakaan kerja memperoleh nilai di tingkat risiko <20 atau Acceptable dengan intensitas kegiatan yang menimbulkan risiko "dikurangi seminimal mungkin". Terdapat 6 (enam) risiko kecelakaan kerja yang dominan yaitu X1.3, X2.3, $\mathrm{X} 2.5, \mathrm{X} 2.8, \mathrm{X} 2.10$, dan X3.2.

\subsection{Fault Tree Analysis (FTA)}

Prediksi kecelakaan dilakukan dengan melakukan FTA. Terdapat 12 penyebab risiko kecelakaan kerja pada pekerja proyek konstruksi yang diperoleh dari kuesioner pakar (lihat Tabel 9).

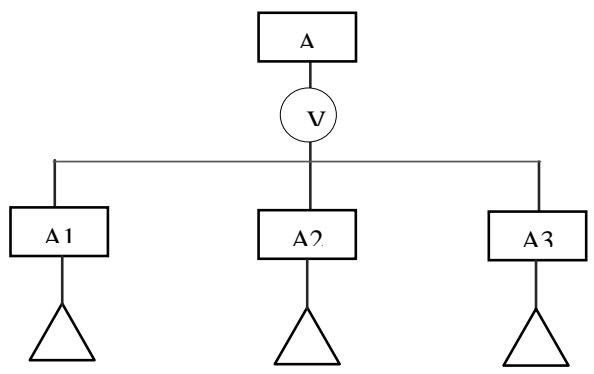

Gambar 1. Diagram FTA top event (A)

dimana A adalah risiko kecelakaan kerja sedangkan A1 adalah jenis pekerjaan bekisting; A2 adalah jenis pekerjaan pembesian; dan A3 adalah jenis pekerjaan pengecoran.

Pada Gambar 1 terlihat hubungan masingmasing kejadian sesuai dengan gerbang gambar yang telah digambarkan. Risiko kecelakaan kerja yang terjadi berdasarkan jenis pekerjaan bekisting, pembesian dan pengecoran. Berdasarkan diagram pada Gambar 1 didapat aljabar Boolean Nilai Risiko (Persamaan 2).

$$
\mathrm{A}=\mathrm{A} 1+\mathrm{A} 2+\mathrm{A} 3
$$

Tabel 9. Daftar Penyebab dari Risiko Kecelakaan Kerja

\begin{tabular}{cl}
\hline & \multicolumn{1}{c}{ Penyebab } \\
\hline P1 & Kurangnya pengetahuan tentang K3 \\
P2 & Metode kerja salah \\
P3 & Pengaman yang kurang sempurna \\
P4 & Penataan material yang tidak rapi \\
P5 & Kebiasaan pekerja yang salah \\
P6 & Kurangnya kepedulian \\
P7 & Tidak kosentrasi dalam bekerja \\
P8 & Tidak Menggunakan APD \\
P9 & Juru ikat tidak kompeten \\
P10 & Tidak menggunakan APD yang sesuai atau pengaman \\
& yang kurang sempurna \\
P11 & Tidak tersedianya akses jalan \\
P12 & Bising dan getaran melebihi NAB \\
\hline
\end{tabular}

Tabel 10. Nilai Risiko dengan Metode Fine

\begin{tabular}{|c|c|c|c|}
\hline No & Risiko Kecelakaan Kerja & Hasil & Comment \\
\hline $\mathrm{X} 1.1$ & $\begin{array}{l}\text { Pekerja tertimpa perancah pada saat } \\
\text { penyusunan }\end{array}$ & 1,5 & Acceptable \\
\hline $\mathrm{X} 1.2$ & $\begin{array}{l}\text { Pekerja jatuh dari ketinggian lebih } \\
\text { dari } 2 \text { meter pada saat } \\
\text { pembongkaran bekisting }\end{array}$ & 1,5 & Acceptable \\
\hline $\mathrm{X} 1.3$ & $\begin{array}{l}\text { Pekerja tersandung material } \\
\text { bongkaran }\end{array}$ & 3 & Acceptable \\
\hline $\mathrm{X} 1.4$ & Kepala terbentur benda keras/tajam & 1,5 & Acceptable \\
\hline $\mathrm{X} 1.5$ & $\begin{array}{l}\text { Tergetok palu pada saat penyusunan } \\
\text { bekisting }\end{array}$ & 1,5 & Acceptable \\
\hline X1.6 & Terbentur cetakan bekisting & 1,5 & Acceptable \\
\hline $\mathrm{X} 1.7$ & Tertimpa alat bantu bongkar/linggis & 1,5 & Acceptable \\
\hline $\mathrm{X} 1.8$ & Tertimpa material bekisting & 1,5 & Acceptable \\
\hline $\mathrm{X} 1.9$ & Pekerja tertusuk paku & 1,5 & Acceptable \\
\hline $\mathrm{X} 1.10$ & $\begin{array}{l}\text { Tangan atau kaki terjepit cetakan } \\
\text { bekisting }\end{array}$ & 1,5 & Acceptable \\
\hline $\mathrm{X} 2.2$ & $\begin{array}{l}\text { Tertusuk besi pada saat pekerjaan } \\
\text { penganyaman besi }\end{array}$ & 1,5 & Acceptable \\
\hline $\mathrm{X} 2.3$ & $\begin{array}{l}\text { Terbentur tulangan pada saat ereksi } \\
\text { tulangan }\end{array}$ & 3 & Acceptable \\
\hline $\mathrm{X} 2.4$ & Pekerja terkena percikan las & 1,5 & Acceptable \\
\hline $\mathrm{X} 2.5$ & Jari tangan terjepit besi & 9 & Acceptable \\
\hline $\mathrm{X} 2.6$ & $\begin{array}{l}\text { Pekerja jatuh dari kerangka } \\
\text { tulangan pada saat memasang dan } \\
\text { merakit tulangan }\end{array}$ & 1,5 & Acceptable \\
\hline $\mathrm{X} 2.7$ & Luka bakar ringan akibat panas besi & 1,5 & Acceptable \\
\hline $\mathrm{X} 2.8$ & $\begin{array}{l}\text { Tersandung saat pekerjaan } \\
\text { pembesian balok dan plat }\end{array}$ & 3 & Acceptable \\
\hline $\mathrm{X} 2.10$ & $\begin{array}{l}\text { Tertimpa besi yang sudah dirakit } \\
\text { saat pengambilan dari Tower Crane }\end{array}$ & 6,25 & Acceptable \\
\hline X3.1 & Tertimpa material beton & 1,5 & Acceptable \\
\hline $\mathrm{X} 3.2$ & $\begin{array}{l}\text { Iritasi mata dan kulit akibat debu } \\
\text { dan kotoran pada saat pemberihan } \\
\text { lokasi cor dengan mesin } \\
\text { Compressor }\end{array}$ & 5 & Acceptable \\
\hline X3.4 & Terbentur bucket cor & 1,5 & Acceptable \\
\hline $\mathrm{X} 3.5$ & $\begin{array}{l}\text { Gangguan pada mata dan } \\
\text { pendengaran akibat getaran vibrator }\end{array}$ & 1,5 & Acceptable \\
\hline $\mathrm{X} 3.7$ & $\begin{array}{l}\text { Gangguan pernapasan akibat } \\
\text { pembersihan area cor dengan mesin } \\
\text { Compressor }\end{array}$ & 1,5 & Acceptable \\
\hline $\mathrm{X} 3.8$ & Mata pekerja terkena percikan beton & 1,5 & Acceptable \\
\hline X3.9 & Terjatuh dari staging cor/ketinggian & 1,5 & Acceptable \\
\hline X3.10 & Terbentur pipa tremi & 1,5 & Acceptable \\
\hline
\end{tabular}




\section{TEKNIK, 41 (2), 2020, 198}

Rincian Aljabar Boolean yang dihasilkan dari Diagram FTA top event untuk masing-masing jenis pekerjaan dapat dilihat pada Tabel 11, 12, dan 13. Aljabar Boolean yang dihasilkan dari Diagram FTA top event untuk jenis pekerjaan bekisting (A1) disajikan pada Tabel 11; untuk jenis pekerjaan pembesian (A2) disajikan pada Tabel 12; sedangkan untuk jenis pekerjaan pengecoran (A3) seperti terlihat pada Tabel 13.

Tabel 14 menunjukkan bahwa dari aljabar Boolean yang telah disusun, kemudian dicari minimal cut set menemukan kombinasi dari beberapa kejadian sampai hasilnya tidak dapat direduksi/disederhanakan lagi. Hasil kombinasi dari kejadian-kejadian tersebut disebut penyebab dari terjadinya top event.

Dari hasil minimal cut set dicari kejadian yang sering muncul sehingga kejadian tersebut merupakan faktor yang dominan menyebabkan kecelakaan kerja pada pekerja proyek konstruksi struktur atas, disajikan dalam tabel 15. Berdasarkan tabel 15, didapat kejadian P1 dan P2 dengan jumlah kejadian yang dominan dari yang lainnya. Sehingga dasar yang menyebabkan terjadinya kecelakaan kerja pada pekerja proyek konstruksi disebabkan oleh kurangnya pengetahuan tentang K3 (Penyebab 1) dan metode kerja yang salah (Penyebab 2).

Upaya yang dapat dilakukan untuk Penyebab 1 adalah dengan membuat workshop setiap aktivitas pekerjaan, Toolbox Meeting, HSE Talk dan Coaching dan untuk Penyebab 2 adalah dengan membuatkan IK (Instruksi Kerja) yang mudah dipahami atau dengan design grafis serta dilakukan sosialisasi kepada pekerja.

\subsection{Validasi Pakar Tahap Akhir}

Dari hasil analisis yang didapat pada Tabel 10, menunjukkan bahwa risiko kecelakaan kerja pada pekerja proyek konstruksi di proyek pembangunan Office Tower J-Box Jakarta berada di nilai tingkat risiko $<20$ atau Acceptable dengan Intensitas kegiatan yang menimbulkan risiko dikurangi seminimal mungkin. Terdapat 6 (enam) risiko kecelakaan kerja yang dominan yaitu X1.3, X2.3, X2.5, X2.8, X2.10, dan X3.2.

Setelah peneliti melakukan validasi kepada pakar (Tabel 16) untuk mengetahui apakah hasil tersebut sudah sesuai dengan kondisi pada proyek Office Tower J-Box Jakarta, maka diketahui bahwa dari 6 (enam) risiko kecelakaan kerja yang dominan, menurut para pakar terdapat 4 (empat) nilai risiko kecelakaan kerja yang sesuai dengan kondisi di proyek pembangunan Office Tower Jakarta Pusat yaitu variabel X1.3, X2.5, X2.8 dan X3.2.
Tabel 11. Aljabar Boolean Jenis Pekerjaan A1

\begin{tabular}{|c|c|}
\hline A1 & $\begin{array}{l}(\mathrm{X} .1 .1 . \mathrm{X} \cdot 1.4 . \mathrm{X} \cdot 1.6)+\mathrm{X} \cdot 1.2+(\mathrm{X} \cdot 1.3 . \mathrm{X} \cdot 1.9) \\
+\mathrm{X} .1 .5+(\mathrm{X} .1 .7 . \mathrm{X} \cdot 1.10)+\mathrm{X} .1 .8) \\
(\mathrm{P} 1 . \mathrm{P} 2)+(\mathrm{P} 1 . \mathrm{P} 2 . \mathrm{P} 3)+(\mathrm{P} 4 . \mathrm{P} 5 . \mathrm{P} 6)+\mathrm{P} 7+ \\
(\mathrm{P} 1 . \mathrm{P} 2 . \mathrm{P} 7)+(\mathrm{P} 1 . \mathrm{P} 2 . \mathrm{P} 9)\end{array}$ \\
\hline X.1.1 = & $\mathrm{P} 1 . \mathrm{P} 2$ \\
\hline $\mathrm{X} .1 .2=$ & $\mathrm{P} 1 . \mathrm{P} 2 . \mathrm{P} 3$ \\
\hline$X .1 .3=$ & P4 . P5 . P6 \\
\hline $\mathrm{X} .1 .4=$ & P1 . P2 \\
\hline $\mathrm{X} .1 .5=$ & P7 \\
\hline $\mathrm{X} .1 .6=$ & P1 . P2 \\
\hline $\mathrm{X} .1 .7=$ & P1. P2 . P7 \\
\hline $\mathrm{X} .1 .8=$ & P1 . P2 . P9 \\
\hline $\mathrm{X} .1 .9=$ & P4 . P5. P6 \\
\hline$X .1 .10=$ & P1 . P2 . P7 \\
\hline
\end{tabular}

Tabel 12. Aljabar Boolean Jenis Pekerjaan A2

\begin{tabular}{|c|c|c|}
\hline A2 & & $\begin{array}{l}\mathrm{X} .2 .2+(\mathrm{X} .2 .3 . \mathrm{X} .2 .10)+\mathrm{X} .2 .4+\mathrm{X} .2 .5+ \\
\mathrm{X} .2 .6+\mathrm{X} .2 .7+\mathrm{X} .2 .8 \\
(\mathrm{P} 1 . \mathrm{P} 2 . \mathrm{P} 7 . \mathrm{P} 8)+(\mathrm{P} 1 . \mathrm{P} 2 . \mathrm{P} 9)+(\mathrm{P} 1 . \mathrm{P} 2)+ \\
(\mathrm{P} 1 . \mathrm{P} 7)+(\mathrm{P} 1 . \mathrm{P} 2 . \mathrm{P} 10)+\mathrm{P} 8+(\mathrm{P} 7 . \mathrm{P} 11)\end{array}$ \\
\hline X.2.2 & $=$ & P1 .P2 . P7 . P8 \\
\hline X.2.3 & $=$ & P1 . P2 . P9 \\
\hline X.2.4 & $=$ & P1 .P2 \\
\hline X.2.5 & $=$ & P1 . P7 \\
\hline$X .2 .6=$ & $=$ & P1 . P2 . P10 \\
\hline$X .2 .7=$ & $=$ & P8 \\
\hline $\mathrm{X} .2 .8=$ & & P7. P11 \\
\hline$X .2 .10=$ & & P1 . P2 . P9 \\
\hline
\end{tabular}

Tabel 13. Aljabar Boolean Jenis Pekerjaan A3

\begin{tabular}{ll}
\hline A3 & $(\mathrm{X} .3 .1 . \mathrm{X} .3 .10)+(\mathrm{X} .3 .2 . \mathrm{X} .3 .7)+\mathrm{X} .3 .4+$ \\
& X.3.5 $+\mathrm{X} .3 .8+\mathrm{X} .3 .9$ \\
& $(\mathrm{P} 1 . \mathrm{P} 2 . \mathrm{P} 9)+(\mathrm{P} 1 . \mathrm{P} 2 . \mathrm{P} 8)+(\mathrm{P} 1 . \mathrm{P} 8)+(\mathrm{P} 10$ \\
& P12 $+(\mathrm{P} 7 . \mathrm{P} 8)+(\mathrm{P} 1 . \mathrm{P} 2 . \mathrm{P} 10)$ \\
$\mathrm{X} .3 .1=$ & $\mathrm{P} 1 . \mathrm{P} 2 . \mathrm{P} 9$ \\
$\mathrm{X} .3 .2=$ & P1.P2.P8 \\
$\mathrm{X} .3 .4=$ & P1.P8 \\
$\mathrm{X} .3 .5=$ & P10.P12 \\
$\mathrm{X} .3 .7=$ & P1.P2.P8 \\
$\mathrm{X} .3 .8=$ & P7.P8 \\
$\mathrm{X} .3 .9=$ & P1.P2.P10 \\
$\mathrm{X} .3 .10=$ & P1.P2.P9 \\
\end{tabular}

Tabel 14. Jumlah Minimal Cut Set

\begin{tabular}{|c|c|c|c|}
\hline No & $\begin{array}{c}\text { Kombinasi } \\
\text { Event }\end{array}$ & No & $\begin{array}{c}\text { Kombinasi } \\
\text { Event }\end{array}$ \\
\hline 1 & $\mathrm{P} 1 . \mathrm{P} 2$ & 11 & P1 . P2 . P10 \\
\hline 2 & P1 . P2 . P3 & 12 & P8 \\
\hline 3 & P4 . P5 . 1P6 & 13 & P7. P11 \\
\hline 4 & P7 & 14 & P1 . P2 . P9 \\
\hline 5 & P1. P2 . P7 & 15 & P1 . P2 . P8 \\
\hline 6 & P1 . P2 . P9 & 16 & P1 . P8 \\
\hline 7 & P1 . P2 . P7 . P8 & 17 & P10. P12 \\
\hline 8 & P1 . P2 . P9 & 18 & P7 . P8 \\
\hline 9 & P1 . P2 & 19 & $\mathrm{P} 1$. P2. P10 \\
\hline 10 & P1.P7 & & \\
\hline
\end{tabular}




\section{TEKNIK, 41 (2), 2020, 199}

Tabel 15. Banyaknya Kejadian Muncul

\begin{tabular}{ccc}
\hline No & $\begin{array}{c}\text { Kombinasi } \\
\text { Event }\end{array}$ & Jumlah \\
\hline 1 & P1 . P2 & 11 \\
2 & P3 & 1 \\
3 & P4 & 1 \\
4 & P5 & 1 \\
5 & P6 & 1 \\
6 & P7 & 6 \\
\hline
\end{tabular}

\begin{tabular}{ccc}
\hline No & $\begin{array}{c}\text { Kombinasi } \\
\text { Event }\end{array}$ & Jumlah \\
\hline 7 & P8 & 5 \\
8 & P9 & 3 \\
9 & P10 & 3 \\
10 & P11 & 1 \\
11 & P12 & 1 \\
\hline
\end{tabular}

Tabel 16. Data Pakar

\begin{tabular}{clcc}
\hline No & \multicolumn{1}{c}{ Jabatan } & $\begin{array}{c}\text { Pengalaman } \\
\text { Kerja }\end{array}$ & Pendidikan \\
\hline 1 & Safety Coordinator & 12 thn & S1 \\
2 & $\begin{array}{l}\text { Health Coordinator } \\
\text { \& Safety }\end{array}$ & 6 thn & S1 \\
3 & Safety Manager & 12 thn & S1 \\
\hline
\end{tabular}

\section{Kesimpulan}

Analisis terhadap hasil penelitian menunjukkan bahwa level risiko dari potensi kecelakaan kerja pada proyek Office Tower Jakarta berada di tingkat risiko $<20$ atau Acceptable. Ini artinya intensitas kegiatan yang menimbulkan risiko sudah dikurangi seminimal mungkin. Terdapat empat risiko kecelakaan kerja yang dominan, yaitu pekerja tersandung material bongkaran, jari tangan terjepit besi, tersandung saat pekerjaan pembesian balok dan plat, serta iritasi mata dan kulit akibat debu dan kotoran saat pembersihan lokasi cor dengan mesin Compressor.

Analisis FTA menghasilkan rekomendasi beberapa tindakan spesifik yang dapat dilakukan oleh pihak kontraktor untuk meminimalisir kecelakaan kerja, yaitu membuat metode kerja yang aman untuk setiap pekerjaan, melakukan tool box meeting sebelum memulai suatu pekerjaan, mengajukan Ijin kerja K3 sebelum melakukan pekerjaan, menggunakan APD yang sesuai untuk setiap pekerjaan, pemasangan ramburambu K3 pada area pekerjaan, dan pengawasan oleh tim HSE.

\section{Daftar Pustaka}

Adityanto, B., Irawan, S., Hatmoko, J. U. D., \& Kistiani, F. (2013). Manajemen Risiko Keselamatan Dan Kesehatan Kerja (K3) Pada Pekerjaan Struktur Bawah Dan Struktur Atas Gedung Bertingkat. Jurnal Karya Teknik Sipil, 2(4), 7384.

Anwar, F. N., Farida, I., \& Ismail, A. (2014). Analisis Manajemen Risiko Kesehatan Dan Keselamatan Kerja (K3) Pada Pekerjaan Upper Structure Gedung Bertingkat (Studi Kasus Proyek Skyland City-Jatinangor). Jurnal Konstruksi, 12(1).
Apriyan, J., Setiawan, H., \& Ervianto, W. I. (2017). Analisis Risiko Kecelakaan Kerja Pada Proyek Bangunan Gedung Dengan Metode FMEA. Jurnal Muara Sains, Teknologi, Kedokteran Dan Ilmu Kesehatan, 1(1), 115-123.

Arikunto, S. (2006). Metodologi Penelitian. Yogyakarta: Bina Aksara.

Bria, T. A., \& Loden, O. (2017). Manajemen Risiko Keselamatan Dan Kesehatan Kerja (K3) Pada Proyek-Proyek Konstruksi Di Kota Kupang. JUTEKS: Jurnal Teknik Sipil, 1(2), 96106.

Christina, W. Y., Djakfar, L., \& Thoyib, A. (2012). Pengaruh Budaya Keselamatan Dan Kesehatan Kerja (K3) Terhadap Kinerja Proyek Konstruksi. Rekayasa Sipil, 6(1), 83-95.

Cross, Jean. 1998. Study Notes: Risk Management. University New South Wales, Sydney.

Dharma, A. A. B., Putera, I. G. A. A., \& Parami, A. A. D. (2017). Manajemen Risiko Keselamatan Dan Kesehatan Kerja (K3) Petitenget Risk Management Of Occupational Health And Safety (K3) In The Development Projects Of Jambuluwuk Hotel \& Resort Manajemen K3. Spektran, 5(1), 47-55.

Fine, W.T. (1973) Mathematical Evaluations For Controlling Hazards, In: Selected Readings In Safety. Academic Press.

Jannah, M. R., Unas, S. E., \& Hasyim, M. H. (2017). Analisis Risiko Keselamatan Dan Kesehatan Kerja (K3) Melalui Pendekatan HIRADC Dan Metode Job Safety Analysis Pada Studi Kasus Proyek Pembangunan Menara X Di Jakarta. Jurnal Mahasiswa Jurusan Teknik Sipil, 1(2), Pp-1138.

Jawat, I. W. (2017). Pengendalian Keselamatan Dan Kesehatan Kerja Pada Proyek Pembangunan Hotel. PADURAKSA: Jurnal Teknik Sipil Universitas Warmadewa, 6(1), 13-33.

Johannes, C. A., Kawatu, P. A., \& Malonda, N. S. (2017). Analisis Penerapan Sistem Manajemen Keselamatan Dan Kesehatan Kerja Di PT. Pembangkit Listrik Nasional (Persero) Wilayah Suluttenggo Sektor Pembangkit Minahasa PLTP Lahendong. Media Kesehatan, 9(3).

Mariawati, A. S., Umyati, A., \& Andiyani, F. (2017). Analisis Penerapan Keselamatan Kerja Menggunakan Metode Hazard Identification Risk Assessment (HIRA) Dengan Pendekatan Fault Tree Anlysis (FTA). Journal Industrial Servicess, 3(1c).

Persada, Y. B. (2015). Hazard Identification And Risk Assessment (HIRA) Kecelakaan Kerja Pada Proses Pengoperasian Scaffolding (Studi Pada 


\section{TEKNIK, 41 (2), 2020, 200}

Proyek Apartemen PT. X Di Surabaya) (Doctoral Dissertation, Universitas Airlangga).

Pitasari, G. I. A. P., Wahyuning, C. S. R. I., \& Desrianty, A. (2014). Analisis Kecelakaan Kerja Untuk Meminimisasi Potensi Bahaya Menggunakan Metode Hazard And Operability Dan Fault Tree Analysis (Studi Kasus Di PT X). Reka Integra,, 2 (2),167-179.

Rahaded, I. N. (2014). Identifikasi Dan Pengendalian Serta Analisis Biaya Resiko Terhadap K3 (Keselamatan Dan Kesehatan Kerja) Pada Proyek Pembangunan Universitas Widya Mandala Pakuwon City Surabaya. EXTRAPOLASI: Jurnal Teknik Sipil, 7(02).

Rethyna, M. (2018). Analisis Risiko Keselamatan Dan Kesehata Kerja (K3) Pada Bangunan Gedung Bertingkat. IKRA-ITH TEKNOLOGI: Jurnal Sains \& Teknologi, 2(1), 20-24.

Safitri, N., \& Widowati, E. (2017). Penerapan Risk Management Pada Pekerjaan Di Ketinggian Berdasar SNI ISO 31000: 2011. HIGEIA (Journal Of Public Health Research And Development), 1(2), 77-88.
Soputan, G. E., Sompie, B. F., \& Mandagi, R. J. (2014). Manajemen Risiko Kesehatan Dan Keselamatan Kerja (K3)(Study Kasus Pada Pembangunan Gedung SMA Eben Haezar). Jurnal Ilmiah Media Engineering, 4(4).

United States Department Of Labor. (2014) Occupational Safety And Health Administration Enforcement. Diakses dari Https://Www.Osha.Gov/Dep/2014_Enforcement Summary.Html

Yolanda, F., Soemirat, J., \& Pharmawati, K. (2014). Perhitungan Kuantitatif Skor Risiko Kecelakaan Menggunakan Metode Fine Dan Matriks Robinson (Studi Kasus PT. X). Institut Teknologi Nasional Bandung, 2(2), 1-12.

Yuliani, U. (2017). Manajemen Risiko Keselamatan Dan Kesehatan Kerja (K3) Pada Infrastruktur Gedung Bertingkat. Jurnal Ilmiah Desain \& Konstruksi, 16(1).

Zulfa, I. M. (2017). Analisis Risiko Ke Analisis Risiko K3 Menggunakan Pendekatan HIRADC Dan JSA (Studi Kasus: Proyek Pembangunan Menara BNI Di Jakarta) (Doctoral Dissertation, Universitas Brawijaya). 